\title{
Evaluation of demographic, clinical and paraclinical characteristics of children with acute disseminated encephalomyelitis
}

\author{
Ahad Ghazavi $^{1^{\circledR}}$, Ezatolah Abbasi ${ }^{2 *(\infty}$, Hashem Mahmodzadeh ${ }^{2}$, Tohid Nasiri $^{3}$ \\ Neurophysiology Research Center, Urmia University of Medical Sciences, Urmia, Iran \\ ${ }^{2}$ Department of Pediatric Neurology, Urmia University of Medical Sciences, Urmia, Iran \\ Urmia University of Medical Sciences, Urmia, Iran
}

\section{*Correspondence to \\ Ezatolah Abbasi, \\ Email:Ezatolahabasi1353@ \\ gmail.com, abbasi.e@umsu. ac.ir}

Received 5 March 2020 Accepted 14 June 2020 Published online 27 July 2020

Keywords: Acute disseminated encephalomyelitis, Children, Viral infection

\begin{abstract}
Introduction: Acute disseminated encephalomyelitis (ADEM) is an immunologically mediated inflammatory demyelinating disorder that commonly occurs following a viral infection or vaccination.

Objectives: This study aimed to evaluate the demographic, clinical and paraclinical characteristics of children with ADEM.

Patients and Methods: In a retrospective study, all children who had a definite diagnosis of ADEM were included in the study. Demographic information (including age and gender), epidemiological features (season of onset, history of previous vaccination and previous infection), clinical signs of ADEM, paraclinical features and also clinical outcomes were extracted from patients' records and entered into a researcher-made checklist. All data were collected, classified and entered into SPSS version 21 for statistical analysis.

Results: A total of 27 patients with ADEM were studied out of which, 16 (59.3\%) were male and 11 (40.7\%) were female. The mean age of patients was $5.21 \pm 4.37$ years, the youngest of which was three months and the oldest patient had 13 years old. The highest incidence (33.3\%) was observed in autumn and $66.7 \%$ of patients had a history of recent infection. Electroencephalographic (EEG) findings were abnormal in $55.6 \%$ of patients. The most common clinical finding of abnormal EEG was motor disorders (51.8\%). Among those who conducted MRI, $71.4 \%$ of them had cortical lesions in the brain. In the majority of cases $(51.9 \%)$, the treatment achieved with intravenous immunoglobulin (IVIG) alone and complete recovery.

Conclusion: The ADEM in this region has relatively similar epidemiological features to those studied worldwide and the favorable treatment of our cases has led to a satisfactory percentage of complete clinical recovery.

Keywords: Acute disseminated encephalomyelitis, Children, Viral infection
\end{abstract}

Citation: Ghazavi A, Abbasi E, Mahmodzadeh H. Evaluation of demographic, clinical and paraclinical characteristics of children with acute disseminated encephalomyelitis. Immunopathol Persa. 2021;7(1):e08. DOI: $10.34172 /$ ipp.2021.08.

\section{Introduction}

Acute disseminated encephalomyelitis (ADEM) is an immunologically mediated inflammatory demyelinating disorder that commonly occurs following a viral infection or vaccination. The clinical symptoms include a range of mild neurological disorders to rapid and fulminant outcomes (1). Symptoms of ADEM often include various neurological and systemic symptoms. Neurological disorders are usually multifocal and often involve changes in mental status and/or altered levels of consciousness (2). Often before encephalopathy, lethargy, headache and vomiting occur. The onset of neurological symptoms is sudden and is characterized by focal motor symptoms, altered levels of consciousness or both (3). Peripheral nerve disorders have also been reported in some cases (4). ADEM can occur at any age, however most cases have reported an average age of between 5 and 8

\section{Key point \\ Acute disseminated encephalomyelitis is accompanied byabnormalelectroencephalographic findings. The most common clinical finding of abnormal EEG was motor disorders and almost most of them have cortical lesions in the brain}

years with mild male gender preference. The reported incidence in the pediatric population is between 0.07 and 0.4 per 100000 per year. Many patients experience a temporary fever before ADEM occurs (5). Magnetic resonance imaging (MRI) shows a significant increase in signal in white matter. The corpus callosum and regions around the ventricle are usually involved. The cerebrospinal fluid (CSF) is often normal. Rare malformations include mild lymphocytic pleocytosis and

\footnotetext{
Copyright (C) 2021 The Author(s); Published by Nickan Research Institute. This is an open-access article distributed under the terms of the Creative Commons Attribution License (http://creativecommons.org/licenses/by/4.0), which permits unrestricted use, distribution, and reproduction in any medium, provided the original work is properly cited.
} 
increased protein concentration (3).

High-dose intravenous methylprednisolone therapy is helpful in approximately $50 \%$ of cases (3). ADEM may reveal as a single lesion, however, $10 \%-29 \%$ of children with early-onset of ADEM will have additional attacks of myelin elimination (6). The prognosis and response to treatment vary in this disease. Childhood ADEM often has favorable outcomes and complete clinical recovery is expected in these conditions, while serious complications in childhood ADEM are rare $(2,7)$. However, a significant recurrence rate of about $2 \%$ to $29 \%$ has been reported for this disease $(8,9)$. ADEM is also the first manifestation of multiple sclerosis (MS), which may occur in $0 \%$ to $57 \%$ of cases $(7,9)$.

Some studies on the characteristics of this disease in the region and especially in our country are not comprehensive and therefore accurate information on the status of this disease in order to manage health planning is important. In one study, the most common early manifestations were ataxia $(60 \%)$, altered consciousness (60\%), fever and vomiting (46\%). CSF abnormalities were found in $70 \%$ of patients. MRI revealed brain lesions in $93 \%$ of subcortical white matter, $80 \%$ of the cerebral cortex, $59 \%$ in the white matter around the ventricle and $47 \%$ in the cerebral cortex and deep gray matter (10). On the other hand, Pohl et al conducted a study on 28 patients under the age of 16 with ADEM in Germany. They found that $65 \%$ of patients had CSF pleocytosis with a mean of CSF white blood cell count of $28 / \mu \mathrm{L}$ and a protein of $40 \mathrm{mg} / \mathrm{dL}$. Additionally, MRI lesions were reported in $86 \%$ of cases. They estimated the incidence of ADEM in children under the age of 16 in Germany to be 0.07 per 100000 of population per year (11).

\section{Objectives}

The present study was designed to evaluate the demographic, clinical and paraclinical characteristics of ADEM among patients referred to a hospital in Urmia during 2010-2016.

\section{Patients and Methods}

Study design and participants

This retrospective study was performed on children with ADEM who referred to Shahid Motahari hospital of Urmia from 2010 to 2016 through a convenience sampling method. All children who had a definitive diagnosis of ADEM were included in the study. Accordingly, all patient records were extracted from the hospital archive and reviewed by a senior medical student (intern). Incomplete, unable to be read records and uncertain cases were excluded. Demographic information (including age and gender), epidemiological features (season of onset, history of previous vaccination and previous infection), clinical signs of ADEM, paraclinical features (including findings obtained from electroencephalography, MRI, CSF fluid analysis, peripheral blood test, erythrocyte sedimentation rate (ESR) and C-reactive protein (CRP) and clinical outcomes (recovery with neurologic complications, complete recovery and mortality) were extracted from patient records and if needed, by contact with patients and entered into a researcher-made checklist.

\section{Ethical issues}

Human rights were respected in accordance with the Helsinki Declaration 1975, as revised in 1983. The informed consent was taken from the patients. The study was approved by ethics committee of Urmia University of Medical Science (Ethical cod\# IR.UMSU.REC.1396.175). This study was extracted from the medical thesis of Tohid Nasiri at this university (Thesis \#96-09-32-2933).

\section{Statistical analysis}

All data were collected and entered into SPSS version 21. Descriptive data were presented in frequency (percentage), mean \pm standard deviation, table and frequency graph.

\section{Results}

In this study, a total of 27 patients with ADEM were studied. Of them, 16 (59.3\%) were male and 11 (40.7\%) were female. The mean age of all patients was $5.21 \pm 4.37$ years, the youngest of which had three months old and the oldest of them was 13 years old. Four patients (14.8\%) were infected in spring, six patients $(22.2 \%)$ in summer, 9 patients (33.3\%) in autumn and 8 patients (29.6\%) in winter. Among them, 18 patients (66.7\%) reported a history of recent infection (up to a month ago) and 9 patients (33.3\%) did not report. Four patients (14.8\%) had a history of recent vaccination (up to a month ago) and 23 patients $(85.2 \%)$ did not mention such a history. Only 9 cases $(33.3 \%)$ had electroencephalography in the patients' records, of which the results of four patients (44.4\%) were normal and the results of five patients (55.6\%) were abnormal. In terms of CSF fluid lymphocyte level, the mean lymphocyte level was $10.13 \pm 25 \%$, since the lowest being zero and the highest being $98 \%$. Thus, 12 (80\%) of the CSF cases showed normal lymphocyte count (below $5 \%$ ) and 3 (20\%) showed abnormal lymphocyte count (above 5\%) (Table 1).

Clinical findings also showed motor disorder in 14 cases (51.8\%), altered consciousness in 9 cases $(33.3 \%)$, headache in 8 cases $(29.6 \%)$, seizures in 10 cases $(37 \%)$, ataxia in 2 cases $(7.4 \%)$ and visual loss in one case (3.7\%) (Figure 1). In terms of polymorphonuclear counts in CSF fluid, the mean polymorphonuclear count was $5.13 \pm 13.45(\times 1000$ / $\mathrm{mm}^{3}$ ) with the lowest being zero and the highest being $45\left(\times 1000 / \mathrm{mm}^{3}\right)$. Moreover, in 13 cases $(86.7 \%)$ the polymorphonuclear count in CSF fluid was normal (zero) and in two cases (13.3\%) was abnormal (greater than zero) (both of which were due to being highly bloody as shown in Table 2).

CSF protein levels were normal (less than $40 \mathrm{mg} / \mathrm{dL}$ ) in nine cases $(60 \%)$ and abnormal in six cases $(40 \%)$ and 
Table 1. Frequency distribution of patients by season

\begin{tabular}{llcc}
\hline Variable & Spring & $\begin{array}{c}\text { Absolute } \\
\text { frequency }\end{array}$ & $\begin{array}{c}\text { Relative } \\
\text { frequency }\end{array}$ \\
\hline \multirow{2}{*}{ Season } & Summer & 4 & $14.8 \%$ \\
& Autumn & 6 & $22.2 \%$ \\
Recent infection & Winter & 9 & $33.3 \%$ \\
history & Yes & 8 & $29.6 \%$ \\
Recent vaccination & Female & 18 & $66.7 \%$ \\
history & Nes & 9 & $33.3 \%$ \\
Electroencephalogram & Normal & 4 & $14.8 \%$ \\
& Abnormal & 23 & $85.2 \%$ \\
\hline \multirow{2}{*}{ Lesion site in MRI } & Brain cortex & 4 & $44.4 \%$ \\
& Midbrain & 5 & $55.6 \%$ \\
& The areas around the & 10 & $71.4 \%$ \\
& ventricle & 1 & $7.1 \%$ \\
& Brain stem & 1 & $7.1 \%$ \\
\hline & Basal ganglia & 1 & $7.1 \%$ \\
\hline
\end{tabular}

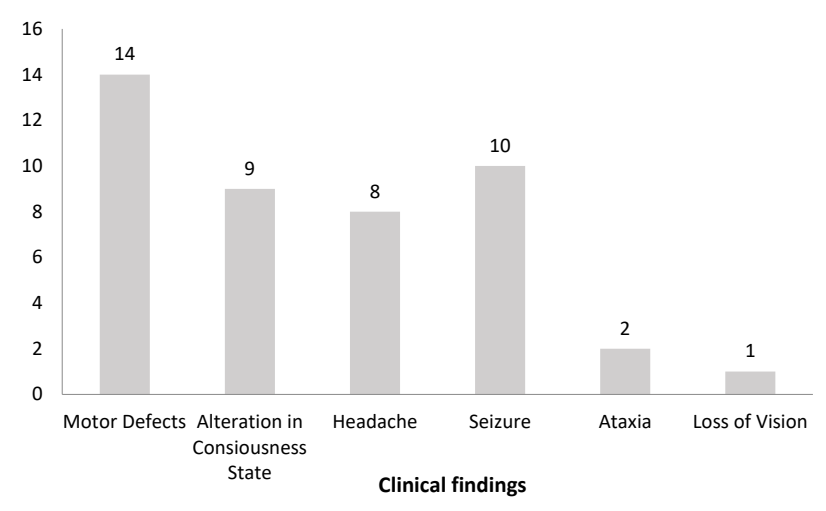

Figure 1. Frequency distribution based on clinical findings.

in terms of glucose levels in CSF fluid, all 15 CSF fluid samples (100\%) had normal glucose levels.

The mean ESR level in all patients was $32.66 \pm 26 \mathrm{~mm} / \mathrm{h}$, the lowest being $3 \mathrm{~mm} / \mathrm{h}$ and the highest of which being $108 \mathrm{~mm} / \mathrm{h}$. Therefore, ESR levels were normal (less than $30 \mathrm{~mm} / \mathrm{h}$ ) in five cases $(18.5 \%$ ) and abnormal (more than $30 \mathrm{~mm} / \mathrm{h})$ in $22(81.5 \%)$ patients. The mean CRP level was $12.15 \pm 20.61 \mathrm{mg} / \mathrm{L}$ in all patients, the lowest of which was zero and the highest was $70 \mathrm{mg} / \mathrm{L}$. Thus, CRP levels in 19 patients $(70.4 \%$ ) were normal (below $10 \mathrm{mg} / \mathrm{L}$ ) and in 8 patients (29.6\%) were abnormal (above $10 \mathrm{mg} / \mathrm{L}$ ). In terms of leukocytosis level, the mean leukocytosis level was $5671.59 \pm 3824.11 / \mu \mathrm{L}$. The lowest amount of it was $1500 /$ $\mu \mathrm{L}$ and the highest amount was $16643 / \mu \mathrm{L}$. Therapeutic modality in 14 patients (51.9\%) was intravenous immunoglobulin (IVIG) alone, in 8 patients (29.6\%) pulse cortisone alone and in 5 patients (18.5\%) was both IVIG and pulse cortisone in combination (Table 2).
Table 2. Frequency distribution for polymorphonuclear counts of CSF liquid

\begin{tabular}{llcc}
\hline Variable & Normal & $\begin{array}{c}\text { Absolute } \\
\text { Frequency }\end{array}$ & $\begin{array}{c}\text { Relative } \\
\text { frequency }\end{array}$ \\
\hline \multirow{2}{*}{ Lymphocyte counts CSF } & 12 & $80 \%$ \\
& Abnormal & 3 & $20 \%$ \\
\hline \multirow{2}{*}{ PMN counts in CSF } & Normal & 13 & $86.7 \%$ \\
& Abnormal & 2 & $13.3 \%$ \\
\hline Protein concentration & Normal & 9 & $60 \%$ \\
in CSF & Abnormal & 6 & $40 \%$ \\
\hline \multirow{2}{*}{ CSF liquid glucose } & Normal & 15 & $100 \%$ \\
\hline \multirow{2}{*}{ Level (mm/hr) ESR } & Abnormal & 0 & 0 \\
\hline \multirow{2}{*}{ Level (mg/L) CRP } & Normal & 5 & $18.5 \%$ \\
& Abnormal & 22 & $81.5 \%$ \\
\hline \multirow{2}{*}{ Therapeutic modality } & Normal & 19 & $70.4 \%$ \\
& Abnormal & 8 & $29.6 \%$ \\
\hline & IVIG & 14 & $52.9 \%$ \\
& Bulse cortisone & 8 & $29.6 \%$ \\
\hline
\end{tabular}

\section{Discussion}

Encephalomyelitis following infection is a common childhood central nervous system disorder that is responsible for 10 to $15 \%$ of all acute encephalitis in the United States (9). ADEM is an immunologically mediated inflammatory demyelinating disorder that commonly occurs following a viral infection or vaccination. The underlying pathology affects the white matter of the central nervous system. The clinical symptoms of this disease are wide, ranging from mild neurological dysfunction to rapid and fulminant outcomes. The prognosis and response to treatment vary. Childhood ADEM often has favorable outcomes and complete clinical recovery is expected (14). However, studies on the characteristics of this disease in the region and especially in Iran are not comprehensive and therefore accurate information on the status of this disease to manage health planning is important. Therefore, our study was designed to evaluate the demographic, clinical and paraclinical characteristics of ADEM among patients referred to Motahari hospital of Urmia between $2010-2016$.

As a result of this study, a total of 27 patients with a diagnosis of ADEM were referred to our center in this period. The mean age of all patients was $5.21 \pm 4.37$ years. The majority of patients were male (59.3\%). The prevalence of the disease was mostly in autumn (33.3\%) and $66.7 \%$ of patients had a history of a recent respiratory tract infection. Electroencephalographic (EEG) findings were abnormal in $55.6 \%$ of those who conducted the electroencephalogram. The most common clinical findings were motor disorders with $51.8 \%$ prevalence. Among the patient who conducted MRI, 71.4\% had cortical lesions. In the majority of cases (51.9\%) only IVIG treatment was applied with complete recovery in $92.6 \%$.

In the study by Murthy et al (13), the authors studied 18 
children with ADEM in New York, similar to the present study, $72 \%$ of patients had recent upper respiratory tract disease. In the present study, however $66.7 \%$ of patients had a history of recent infection. In a study by Samile and Hassan et al (10), 46.4\% of patients had a history of upper respiratory tract disease while similar to our study; a low percentage (13.6\%) had a recent vaccination history. Therefore, it can be concluded that recent infection in children can be considered as one of the causes in association with or before ADEM.

We also found gender predominance was favored by the males, whereas in similar studies, including the study by McDonald et al (17), Murthy et al (13), Chakravarty (18) and Ozawa et al (19) there was no gender prevalence. Although the prominence was not very significant in our study, it points out to a different distribution of the disease across the region.

The study by Lin et al (15) showed, among the 42 ADEM patients, the most common symptoms included muscle weakness and loss of speech and bulbar symptoms. In the study by Visudtibhan et al (14), the authors examined 16 patients with ADEM, which $31.3 \%$ of the patients had pleocytosis and $31.3 \%$ showed increased protein in CSF fluid. We found elevated protein levels of CSF fluid in $55.6 \%$ of the patients while pleocytosis was observed in $13.3 \%$ of them. Similarly in the study of Lin et al (15) CSF abnormalities including pleocytosis and total protein increase were reported in $66.7 \%$ of children. Accordingly, in the study of Torisu et al (16), pleocytosis and increased protein in CSF fluid were reported in $81 \%$ and $35 \%$ of the patients with ADEM, respectively. The cause of the differences in reported prevalence can be explained by differences in studied populations and consequently racial differences between studied populations, differences in laboratory kits along different time periods of study.

The study by Anlar et al (8), examined the outcomes and prognosis of ADEM in children. They found among 46 patients with this disease who were followed for one year, $71 \%$ had a complete recovery. In similar studies also, the complete recovery interval ranged from 57 to $81 \%(2,20$ 22 ). However, our results showed the overall recovery rate was $92.6 \%$.

This percentage primarily reflects the good performance of the studied center in the treatment of patients with ADEM, however compared to the higher percentage than the global average, it can be attributed to the lower sample size, lower follow-up time and different criteria in studies to define complete recovery of the disease.

\section{Conclusion}

It can be concluded that ADEM in this region has relatively similar epidemiological features to those in the world studied and the favorable performance of the region's treatment system has resulted in a satisfactory percentage of complete clinical outcomes in these patients. Therefore, it is recommended that current treatment in the future be maintained in the region and such studies be carried out in different regions of the country by examining higher sample sizes and also cohort studies should be conducted to follow longer-term complications.

\section{Limitations of the study}

Totally, 27 patients with ADEM were studied. The major limitation of this study is small sample size due to the rarity of the disease.

Authors' contribution

AG and EA were the main investigators, collected the data and wrote the first draft. TN and HM designed the study, and also read and corrected the draft. All authors read and signed the final manuscript.

\section{Conflicts of interest}

The authors declare that they have no conflicting interest.

Ethical considerations

Ethical issues (including plagiarism, double publication) have been completely considered by the authors.

\section{Funding/Support}

The author would like to thank the vice chancellor for research in Urmia University of Medical Science to support the medical thesis with code 96-09-32-2933.

\section{References}

1. Johnson RT. The pathogenesis of acute viral encephalitis and postinfectious encephalomyelitis. J Infect Dis. 1987;155:359-364. doi: 10.1093/infdis/155.3.359

2. Tenembaum S, Chitnis T, Ness J, Hahn JS. International Pediatric MS Study Group. Acute disseminated encephalomyelitis. Neurology. 2007;68:S23-S36. doi: 10.1212/01. wnl.0000259404.51352.7f.

3. Piña-Garza JE. Fenichel's Clinical Pediatric Neurology: A Signs and Symptoms Approach: Elsevier Health Sciences; 2013.

4. Amit R, Glick B, Itzchak Y, Dgani Y, Meyeir S. Acute severe combined demyelination. Childs Nerv Syst. 1992;8:354-56. doi: 10.1007/BF00296569.

5. Kliegman RM SB, St Geme III JW, Schor NF, Behrman RE. Nelson Textbook of Pediatrics. 20th ed. Philadelphia: Elsevier; 2016.

6. Swaiman KF AS, Ferriero DM, Schor NF. Swaiman's Pediatric Neurology. 5th ed. Philadelphia: Elsevier Saunders; 2012.

7. Mikaeloff Y, Adamsbaum C, Husson B, Vallée L, Ponsot G, Confavreux $\mathrm{C}$, et al. MRI prognostic factors for relapse after acute CNS inflammatory demyelination in childhood. Brain. 2004;127:1942-7. doi: 10.1093/brain/awh218.

8. Anlar B, Basaran C, Kose G, Guven A, Haspolat S, Yakut A, et al. Acute disseminated encephalomyelitis in children: outcome and prognosis. Neuropediatrics. 2003;34:194-9. doi: 10.1055/s-2003-42208.

9. Hung K-L, Liao H-T, Tsai M-L. Postinfectious encephalomyelitis: etiologic and diagnostic trends. JChild Neurol. 2000;15:666-70. doi: 10.1177/088307380001501005.

10. Samile N, Hassan T. Acute disseminated encephalomyelitis in children. A descriptive study in Tehran, Iran. Saudi Med J. 2007;28:396-9.

11. Pohl D, Hennemuth I, Von Kries R, Hanefeld F. Paediatric multiple sclerosis and acute disseminated encephalomyelitis in Germany: results of a nationwide survey. Euro J Pediat. 2007;166:405-12. doi: 10.1007/s00431-006-0249-2.

12. Xiong $\mathrm{CH}$, Yan $\mathrm{Y}$, Liao $Z$, Peng $\mathrm{SH}$, Wen $\mathrm{HR}$, Zhang $\mathrm{Y}$, et 
al. Epidemiological characteristics of acute disseminated encephalomyelitis in Nanchang, China: a retrospective study. BMC Public Health. 2014;14:111. doi: 10.1186/1471-2458$14-111$

13. Murthy SN, Faden HS, Cohen ME, Bakshi R. Acute disseminated encephalomyelitis in children. Pediatrics. 2002;110:e21. doi:10.1542/peds.110.2.e21

14. Visudtibhan A, Tuntiyathorn L, Vaewpanich J, Sukjit P, Khongkatithum C, Thampratankul L, et al. Acute disseminated encephalomyelitis: a 10-year cohort study in Thai children. Eur J Paediatr Neurol. 2010;14:513-518. doi: 10.1016/j. ejpn.2010.02.010

15. Lin CH, Jeng JS, Hsieh ST, Yip PK, Wu RM. Acute disseminated encephalomyelitis: a follow-up study in Taiwan. J Neurol Neurosurg Psychiatry. 2007;78:162-7. doi: 10.1136/ jnnp.2005.08419

16. Torisu H, Kira R, Ishizaki Y, Sanefuji M, Yamaguchi $Y$, Yasumoto $\mathrm{S}$, et al. Clinical study of childhood acute disseminated encephalomyelitis, multiple sclerosis, and acute transverse myelitis in Fukuoka Prefecture, Japan. Brain Dev. 2010;32:454-462. doi:10.1016/j.braindev.2009.10.006

17. McDonald WI, Compston A, Edan G, Goodkin D, Hartung HP, Lublin FD, et al. Recommended diagnostic criteria for multiple sclerosis: guidelines from the International Panel on the diagnosis of multiple sclerosis. Ann Neurol. 2001;50:121-7. doi: 10.1002/ana.1032

18. Chakravarty A. Neurologic illness following post-exposure prophylaxis with purifiled chick embryo cell antirabies vaccine. J Associat Physic India. 2001;49:927-8.

19. Ozawa H, Noma S, Yoshida Y, Sekine H, Hashimoto T. Acute disseminated encephalomyelitis associated with poliomyelitis vaccine. Pediatr Neurol. 2000;23:177-9. doi: 10.1016/s08878994(00)00167-3.

20. Apak RA, Köse G, Anlar B, Turanli G, Topaloğlu H, Ozdirim E. Acute disseminated encephalomyelitis in childhood: report of 10 cases. J Child Neurol. 1999;14:198-201. doi: 10.1177/088307389901400312.

21. Dale RC, de Sousa C, Chong WK, Cox TC, Harding B, Neville BG. Acute disseminated encephalomyelitis, multiphasic disseminated encephalomyelitis and multiple sclerosis in children. Brain. 2000;123 Pt 12:2407-22. doi: 10.1093/ brain/123.12.2407.

22. Hynson JL, Kornberg AJ, Coleman LT, Shield L, Harvey AS, Kean MJ. Clinical and neuroradiologic features of acute disseminated encephalomyelitis in children. Neurology. 2001;56:1308-12. doi: 10.1212/wnl.56.10.1308 